\title{
PREVENTING DAMAGING PRESSURE GRADIENTS AT THE WALLS OF AN INFLATABLE SPACE SYSTEM.
}

\author{
John J. Scialdone \\ NASA's Goddard Space Flight Center \\ Greenbelt, MD 20771
}

ABSTRACT

An inflatable structural system to deploy a space system such as a solar shield, an antenna or another similar instrument, requires a stiffening element after it is extended by the inflated gas pressure. The stiffening element has to be packaged in a folded configuration before the deployment. It must be relatively small, lightweight, nondamaging to the inflated system, and be able to become stiff in a short time. One stiffening method is to use a flexible material inserted in the deployable system, which, upon a temperature curing, can become stiff and is capable to support the entire structure. There are two conditions during the space operations when the inflated volume could be damaged: during the transonic region of the launch phase and when the curing of the rigidizing element occurs. In both cases, an excess of pressure within the volume containing the rigid element could burst the walls of the low-pressure gas inflated portion of the system.

This paper investigates those two conditions and indicates the vents, which will prevent those damaging overpressures. Vent openings at the non-inflated volumes have been calculated for the conditions existing during the launch. Those vents allow the initially folded volume to exhaust the trapped atmospheric gas at approximately the same rate as the ambient pressure drops. That will prevent pressure gradients across the container walls which otherwise could be as high as $14.7 \mathrm{psi}$.

The other condition occurring during the curing of the stiffening element has been investigated. This has required the testing of the element to obtain the gas generation during the curing and the transformation from a pliable material to a rigid one. The tested material is a composite graphite/epoxy weave. The outgassing of the uncured sample at $121{ }^{\circ} \mathrm{C}$ was carried with the Cahn Microbalance and with other outgassing facilities including the micro-CVCM ASTM E-595 facility. The tests provided the mass of gas evolved during the test. That data, including the chemical nature of the evolved gas, provided the data for the calculation of the pressure produced within the volume. The evaluation of the areas of the vents that would prevent excessive pressures and provide a rapid release of the gas away from contamination sensitive surfaces has been carried out. The pressure decay with time has been indicated.

Keywords: Inflatable Space Systems; Stiffening Member; Material Curing; Gaseous Venting

\section{INTRODUCTION}

Inflatable systems to be deployed in space for the protection of spacecraft against certain radiation and for the deployment of research instruments for the measurement of the natural or induced environment in space are being used or proposed. Their uses have increased due to the volumetric and weight limitations of the launch to space capabilities. The inflatable systems are made of lightweight polymeric materials. They occupy small 
volumes when in a non-extended retrieved condition. They may have a limited strength resistance to physical loads and they require to be stiffened when deployed. The stiffening devices will keep the gas-inflated systems rigid and stable for the intended functions. They may be required to maintain extended and rigid the system in the event of loss of the inflating gas pressure. The stiffening element may consist of an initially rolled strip which, when extended by the inflation process and heated by an electrical resistance heater, chemically cures and becomes rigid. The curing process results in the release of gaseous products from the material. A large amount of the outgassing may produce a sufficiently high pressure within the volume containing the stiffening element. The resulting pressure differentials may be sufficient to rupture the walls of the inflated volume (figures 1,2 ). The escape of the gas may result in an unwanted propulsive spacecraft disturbance and the possible deposit of the gas on critical surfaces. For these reasons, tests were carried out to measure the amount and the nature of the gas released during the temperature curing of a proposed composite graphite/epoxy material. Those results have been used to evaluate the vent sizes, which will limit the pressure in the volume. Accordingly the maximum acceptable gradient of pressure across the inflated volume wall has been provided. Another condition during flight when a pressure differential could be sufficiently high has also been considered. During the transonic region of the launch phase, the rapid external pressure drop may cause unacceptable pressure differentials across a volume. The differential pressure could be as high as 14.7 psi.

\section{EXPERIMENTAL}

Figure 4 shows the mass loss versus time of a $1 \mathrm{in}^{2}\left(6.45 \mathrm{~cm}^{2}\right)$ sample of graphite/epoxy composite weave. The appearance of the weave is shown in figure 3 . The mass loss carried with a Cahn analytical Microbalance at a pressure of $10^{-7}$ torr and at the indicated temperature of $121^{\circ} \mathrm{C}$ was $33.52 \mathrm{mg}$ after 24 hours (Figure 5). The loss occurred within an hour of the initiation of the test and the rapid mass loss lasted about $32 \mathrm{~min}$. The mass loss is represented by the equation $\mathrm{m}=75.181 \mathrm{t}-18.254$ (mg) where $\mathrm{t}$ is in hours. The resulting rate of gas release obtained by differentiation of the mass loss versus time was $11.65 \mathrm{mg} / \mathrm{hr} / \mathrm{cm}^{2}$. The mass loss test was repeated several times and the results were confirmed using other test facilities. The indicated $3924 \mathrm{in}^{2}\left(25316 \mathrm{~cm}^{2}\right)$ area of the stiffening element at the above rate would produce a total outgassing rate of about $\mathrm{m}=2.95 \times 10^{2} \mathrm{~g} / \mathrm{hr}$ within the volume. Analysis of the residue collected on the QCM microbalance surface indicated the deposit to be the catalyst dicyandiamide. The condensable fraction of the outgassing at a temperature of $-25^{\circ} \mathrm{C}$ as measured by a crystal microbalance is also shown in figure 4 . The total amount of the condensable at that temperature is obtainable by accounting for the view factor of the microbalance with respect to the material test sample. As shown on the same figure 4 , the products deposited on the QCM at $-25^{\circ} \mathrm{C}$ can be removed at different rates when employing temperatures of 25,45 and $65^{\circ} \mathrm{C}$. These data may be needed for the evaluation of possible contamination of surfaces adjacent to the inflated system and for indications on the temperatures needed for its removal. 


\section{ANALYSIS}

The total outgassing rate of $2.95 \times 10^{2} \mathrm{~g} / \mathrm{hrs}$ changed in to $\mathrm{pv}$ units at a temperature $\mathrm{T}=394{ }^{\circ} \mathrm{K}$ with the assumption that the mole mass is $\mathrm{M}=36 \mathrm{~g} /$ mole corresponds to a throughput, $\mathrm{Q}_{0}=\mathrm{m} \mathrm{P}_{0} \mathrm{~V}_{0} \mathrm{~T} / \mathrm{MT}_{0}=2.95 \times 10^{2}(\mathrm{~g} / \mathrm{hr}) \times(760 \times 22.4 \times 394 / 36 \times 273)$ (torr $\mathrm{V} / \mathrm{g}$ ) $=2.01 \times 10^{5}$ (torr $\left.\mathrm{l} / \mathrm{hrs}\right)=55.83$ torr $\mathrm{l} / \mathrm{s}$.

The pressure developed within the volume can be found based on a vent orifice passage of area $A\left(\mathrm{~cm}^{2}\right)$ having a conductance in the viscous flow region given by $C=20 \mathrm{~A}(1 / \mathrm{s})$ (Ref. 1). This conductance is valid for air at $20^{\circ} \mathrm{C}$ and when the ratio of the downstream to the upstream pressure is less than 0.1. In the present application the above conductance modified for the temperature and molecular mass will be $\mathrm{C}=20$ $(394 \times 28 / 293 \times 36)^{1 / 2} \mathrm{~A}=20 \times 1.04 \mathrm{~A}=20.8 \mathrm{~A}(\mathrm{~V} / \mathrm{s})$. The viscous flow of gas at a pressure $\mathrm{P}$ via the orifice of area $A$ is then $Q=20.8 \mathrm{~A} \mathrm{P}$ (torr $1 / \mathrm{s}$ ). The pressure in the volume containing the curing element will be $\mathrm{P}=\mathrm{Q}_{\alpha} / 20.8 \mathrm{~A}=55.83 / 20.8 \times 5=0.53$ torr $(.01 \mathrm{psi})$ when a $5 \mathrm{~cm}^{2}$ vent area is provided. This pressure is order of magnitude lower than the acceptable 0.5 psid ( 25.8 torr). The required $5 \mathrm{~cm}^{2}$ vent area can be made up from a number of small vents. In that case, the total vent area should be increased to account for the discharge coefficient with a value of about 0.6 for each vent.

After the 32 minutes the release of gas continues as shown by the test at a rate of about $0.15 \mathrm{mg} / \mathrm{hr} / \mathrm{in}^{2}$. Accounting for the total area of the curing element, the total rate is $1.64 \times 10^{-4} \mathrm{~g} / \mathrm{s}$ or in pv units $\mathrm{Q}=1.64 \times 10^{-4} \times 682=0.11$ torr $\mathrm{V} / \mathrm{s}$ and the quasi-steady pressure in the volume will be $\mathrm{P}=0.11 / 20.8 \times 5=1.05 \times 10^{-3}$ torr.

With regard to the behavior of the material released during curing, the constant rate of mass loss implies that the curing process follows a zero order chemical reaction, and the mass loss rate is a function of the vapor pressure at the curing temperature. The vapor pressure at $379^{\circ} \mathrm{K}$ for the material with a molecular mass $\mathrm{M}=36(\mathrm{~g} / \mathrm{mole})$ and with an outgassing rate of $\mathrm{m}=3.26 \mathrm{~g} / \mathrm{cm}^{2} / \mathrm{s}$, can be calculated (Ref.2) to be $\mathrm{P}=17.14 \mathrm{~m}(36 / 379)^{-1 / 2}$ $=1.85 \times 10^{-4}$ torr

The other condition, which may result in a damage, occurs during the transonic region of the launch phase of the flight. At that time, when the system is in a stowed condition and the external pressure is about 6 psi, depending on the location of the payload, a rapid rate of pressure drop of about $0.75 \mathrm{psi} / \mathrm{s}$ may develop. It lasts about $5 \mathrm{~s}$ and a pressure gradient across the walls of a volume may develop if the volume cannot vent at the same rate of the outside. A volume-vent area combination is required to permit the combination to respond at the same rate of the outside. The equation employed by the author (Ref. 3) to estimate the required vent area for a volume $V\left(\mathrm{~m}^{3}\right)$ is

$$
A=V / C_{d}\left[2 g R T P_{o} \Delta P / P^{2}\right]^{1 / 2} \ldots \ldots \ldots\left(m^{2}\right)
$$

Where $g=9.81 \mathrm{~m} / \mathrm{s}^{2}, R=29.2 \mathrm{~m} / \mathrm{K}$ is the gas constant, $T(K)$ is the temperature, $P_{o}$, the pressure when the rate of pressure drop $\mathrm{P}$ (psi/s) occurs, $\Delta \mathrm{P}$ (psi) is the acceptable pressure differential and $C_{d}=0.6$ is the vent orifice discharge coefficient. Inserting the values indicated one gets that, for an acceptable $\Delta P=0.5 \mathrm{psi}$, the required vent area is $A=$ V/615.97 $\left(\mathrm{m}^{2}\right)$. Then, for an indicated volume of $378 \mathrm{in}^{3}\left(6.205 \mathrm{~cm}^{3}\right)$, the required vent area is $A=1.0 \times 10^{-5} \mathrm{~m}^{2}=1 \mathrm{~cm}^{2}$ i.e., an orifice with diameter $\mathrm{d}=0.357 \mathrm{~cm}$. 
In terms of system response time, the above combination of volume-orifice will have a response of

$\tau=V / 20.8 \mathrm{~A}=6.2 / 2=3.08 \mathrm{~s}$

This response time is less than the $5 \mathrm{~s}$ duration of the pressure disturbance and the system can accommodate the 0.5 psi pressure differential during the launch phase of the flight. It is expected that the volumes making up the above combined volume will be provided with passage areas leading into the large volume sufficiently large to have volumepassage response time of about $3 \mathrm{~s}$.

\section{CONCLUSIONS}

The prevention of overpressure in an inflatable support system during the thermal curing of a stiffening element has been investigated. The amount of gas evolved during the temperature curing of the stiffening element was measured using the Cahn analytical microbalance. The chemical nature, the condensable products at $-25 \mathrm{C}$ of the evolved gas and the removable rate of those at 25,45 and $65^{\circ} \mathrm{C}$ were measured. The vapor pressure of the material at $121^{\circ} \mathrm{C}$ was calculated to be about $1.05 \times 10^{-4}$ torr. The analysis showing the required vent area to limit the pressure buildup in the deployed volume resulting from the evolved gas was calculated. It was calculated that a $5 \mathrm{~cm}^{2}$ vent orifice can limit the pressure to about $0.01 \mathrm{psi}$ ( 0.56 torr), much less than the acceptable 0.5 psid (25.5 torr). The long-term pressure in the volume due to residual outgassing after the curing was calculated to be about $1 \times 10^{-3}$ torr.

The other vent area required for the venting of the folded launch condition of the deployable system has also been calculated. A vent orifice having a diameter of 0.357 $\mathrm{cm}$ is needed to prevent an internal pressure of 0.5 psi during the transonic region of the launch flight when a high rate of pressure drop may exist external to the packaged system. The methods to carry out these analyses for the vent requirements and the evaluation of the outgassing rate during curing have been indicated.

\section{REFERENCES}

.1 Donald J. Santeler, D.H Holkeboer, D.W.Jones and F.Pagano, - "Vacuum Technology and Space Simulation " NASA SP-105, 1966 page 71,76 and 93

2 Alfred E. Barrington, "High Vacuum Engineering " Prentice -Hall,Englewood Cliffs,N.J.,pag.21

3 John J. Scialdone, "Spacecraft Compartment Venting" Proceedings of SPIE, July 1998 San Diego, California, Vol.3427, Page23. 

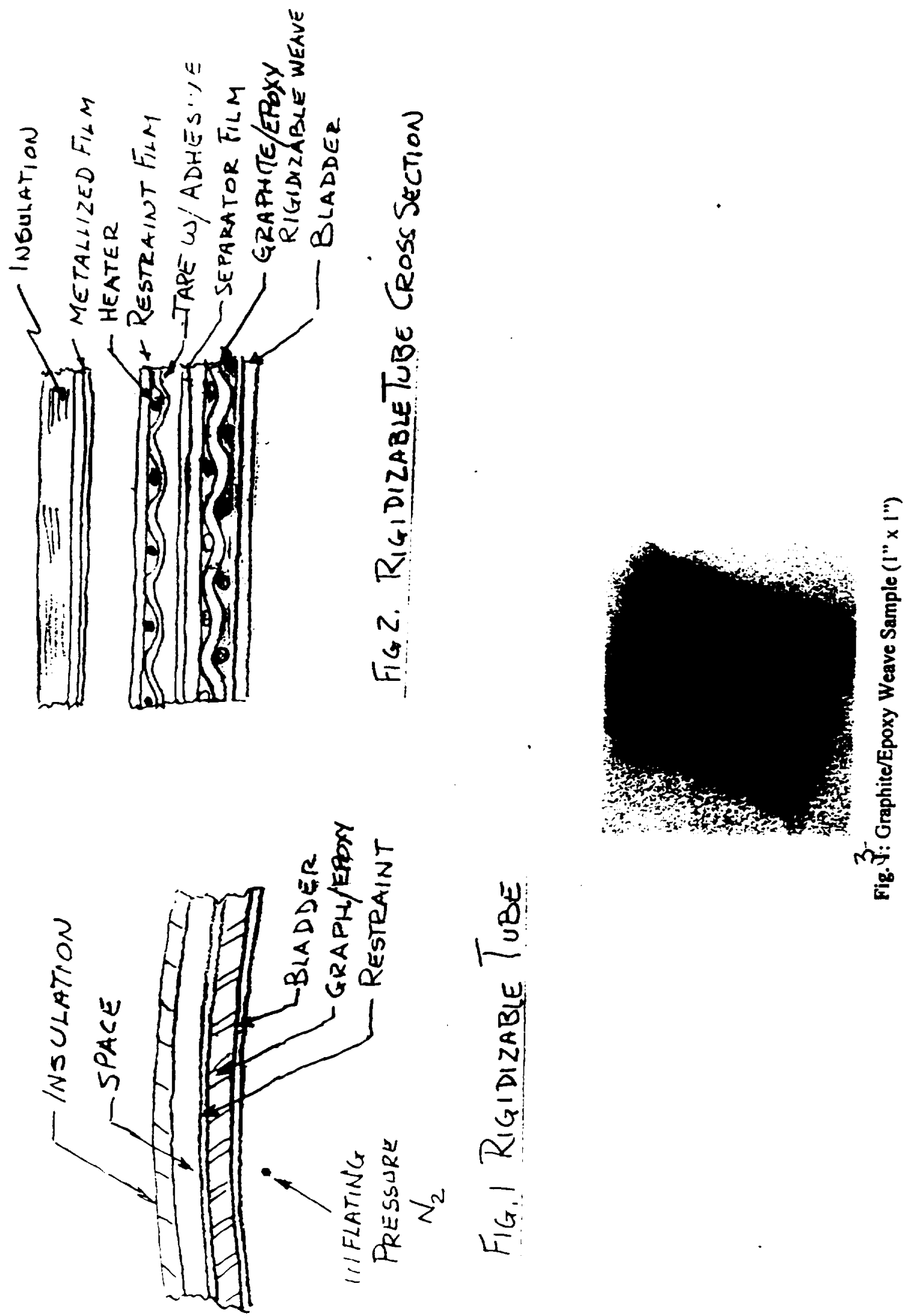


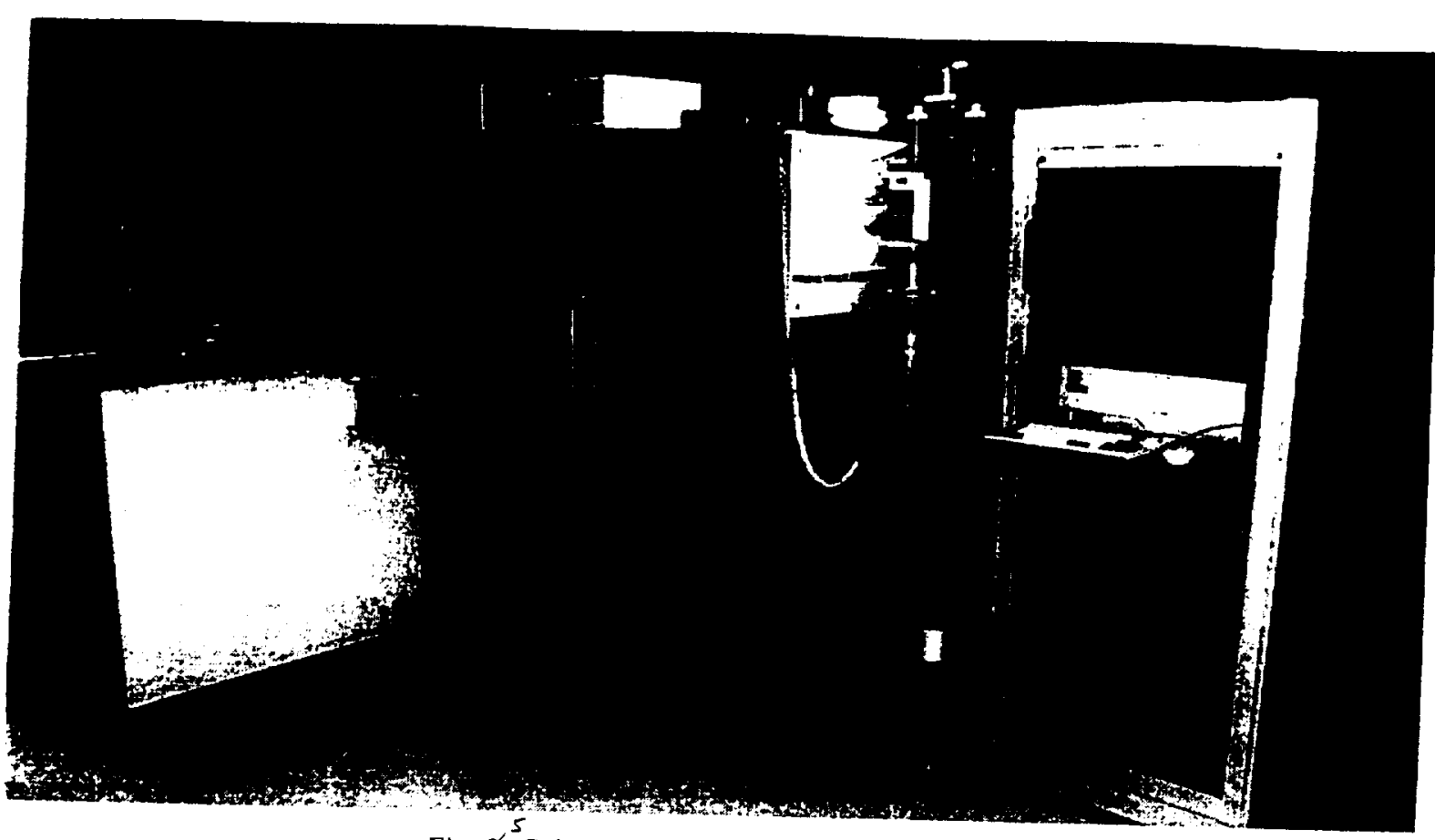

Fig. $2^{5}$ CahniQCM RGA Outgassing Facility

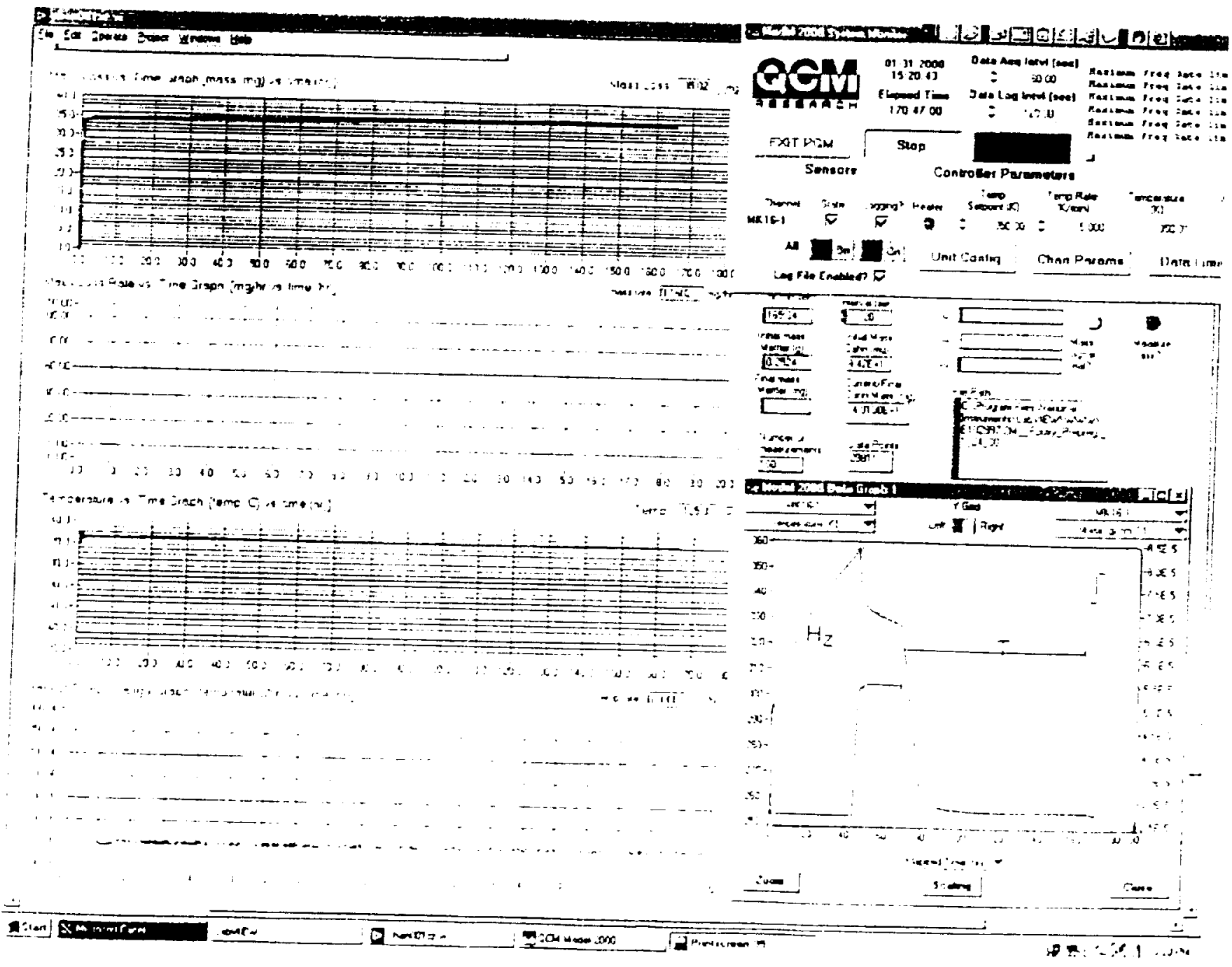

